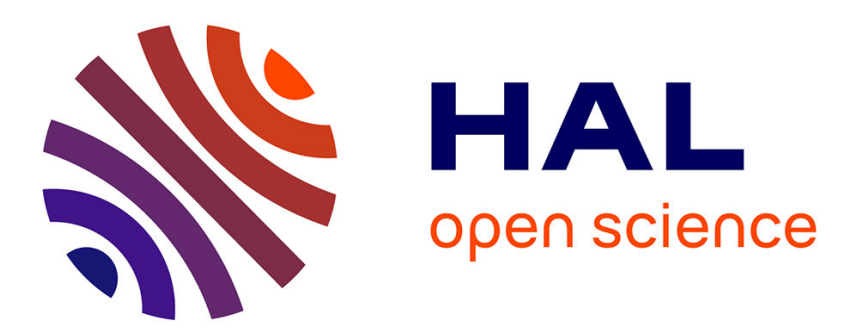

\title{
A Parallel Architecture Approach to Spanish Verbal Derivation with the Causative Prefix en-
}

Ernesto Wong García

\section{To cite this version:}

Ernesto Wong García. A Parallel Architecture Approach to Spanish Verbal Derivation with the Causative Prefix en-. Forum for Modern Language Studies, 2019, 55 (1), pp.90-116. 10.1093/fmls/cqy065. hal-03318414

\section{HAL Id: hal-03318414 https://hal.science/hal-03318414}

Submitted on 10 Aug 2021

HAL is a multi-disciplinary open access archive for the deposit and dissemination of scientific research documents, whether they are published or not. The documents may come from teaching and research institutions in France or abroad, or from public or private research centers.
L'archive ouverte pluridisciplinaire HAL, est destinée au dépôt et à la diffusion de documents scientifiques de niveau recherche, publiés ou non, émanant des établissements d'enseignement et de recherche français ou étrangers, des laboratoires publics ou privés. 


\title{
A Parallel Architecture Approach to Spanish Verbal Derivation with the Causative Prefix en-
}

\author{
Ernesto Wong García, School of Foreign Languages, University of Havana, Cuba \\ 19 de Mayo \#14, bt. Ayestarán and Amézaga, Plaza de la Revolución, Havana
}

Correspondence: ewong@flex.uh.cu

Word count: 8851

Published version: Wong García, E. (2019). A Parallel Architecture Approach to Spanish Verbal Derivation with the Causative Prefix En-. Forum for Modern Language Studies, 55(1), 90-116. https://doi.org/10.1093/fmls/cqy065 


\section{Abstract:}

This paper presents an analysis of a corpus of Spanish causative verbs formed with the prefix en-, framed in terms of the Parallel Architecture (PA) theory. By segmenting the units, we identify five specific morphological schemas, all instances of a single general schema. By analysing dictionary definitions, we identify one general meaning schema, realized in nine specific schemas, which are modelled using the tools of Conceptual Semantics. By analysing how these verbs behave in sentences, we identify one general syntactic schema, realized in three specific schemas. We also look at the sound structure of these verbs, and explore the links between the three kinds of structure (sound, syntax, and meaning), the production of redundancies (or lack thereof) when the verbs take complements, and we formulate the problems of predicting the meaning of the verb from the meaning of the base, and of accounting for figurative meanings.

Keywords: causative verbs; causative prefix; Spanish morphology; Parallel Architecture; Conceptual Semantics 


\section{Introduction: The Parallel Architecture}

This paper presents the analysis of a corpus of Spanish causative verbs formed with the prefix $e n-$. The study falls within the Parallel Architecture (PA) framework, which offers a view of the object that, as far as we know, has not previously been explored.

The PA is a theoretical framework for the study of language, developed mainly by Ray Jackendoff $^{1}$, in which the main components of language — semantics, phonology and syntax - are all generative in nature and interact with one another through interfaces. The PA thus sets itself apart from other frameworks, notably Chomskian generative linguistics, which take syntax to be the only generative component of language.

The PA does away with a distinction that has persisted in other theories of language, between lexical units (prototypically "words") and rules (prototypically combinatorial). Within this framework, "words" (lexemes, monemes, Saussurean signs, etc.) are themselves analysed as rules, in this case, interface rules specifying the links between pieces of structure produced by the three generative components. Thus, any given word, and, indeed, any fragment of language, appears (ideally ${ }^{2}$ ) as the interconnection of a piece of phonological structure (how it is pronounced), a piece of semantic structure (what it means), and a piece of syntactic structure (how it combines with other words).

This view also makes it possible for the lexicon of a language to include not only words and idioms, but also smaller units such as morphemes.

Within the PA, morphology is not seen as an autonomous component of the language faculty. Morphemes are themselves lexical units, and they are analysed as interface rules that link phonological, semantic, and syntactic structures. A continuity is thus established from smaller (morphemes) to larger units (words, idioms, etc.).

Works on PA morphology ${ }^{3}$, in keeping with the general PA framework, code the rules of grammar in the form of schemas: pieces of linguistic structure containing variables. Thus conceived, morphology appears as a grammar of words and their constituents, including morphosyntax and its interfaces with lexical phonology, lexical semantics, and phrasal syntax.

\section{Conceptual Semantics}

Within the PA, the semantic structures of language are described by the theory of Conceptual Semantics (CS). Two aspects of this theory are necessary for understanding the results presented here: ontological classes and semantic functions.

The fragments of reality denoted by language are organized into ontological classes (kinds of things). We thus have the opposition between Events (bounded in time) and States 
(unbounded in time), and between Objects (bounded in space) and Substances (unbounded in space); Properties, Shapes and Positions; Places (spatial locations) and Paths (which define movement). For the purpose of the present analysis, we introduce here two particular kinds of States: Mental States (MStates) and Physical States (PhStates). Among Mental States, we will distinguish between those that are intentional (directed at an object), such as love or jealousy, and those that are non-intentional, such as sadness or boredom.

These ontological classes serve as arguments for the semantic predicates or functions that structure meaning. The semantic structures of language are therefore analysed not as sets of necessary and sufficient features (in the tradition of structural semantics), but as complex combinations of smaller units of meaning in hierarchical arrangements. These smaller units (functions or predicates) are primitives, the meaning of which is exhausted by their ability to combine with other primitives and by the inference and interface rules that they license ${ }^{4}$. We present here the ones we use in the analysis.

Our main function is evidently the function CAUS (X, F), which denotes a causation Event, and whose first argument $\mathrm{X}$ takes the role of Agent of the causation. Its second argument is another function whose first argument usually takes the role of Theme (the affected object, the causee).

We use a group of spatial functions. Unless otherwise noted, they are regularly used in PA Conceptual Semantics. The first one, which can be an argument of CAUS, is GO (Y, F). This function denotes a movement Event. Its first argument $Y$ takes the role of Theme (moving entity), and its second argument is one of the following spatial functions:

- $\quad \mathrm{TO}(\mathrm{F})$ denotes a Path, and its argument $\mathrm{F}$ is a Place function, which takes here the role of Goal (although it can also be a Source).

- IN (Z) denotes a Place, and its argument $Z$ is an Object with a defined interior space. The meaning of a verb like engavetar ('to put in a drawer'), for example, can thus be semi-formally modeled as CAUS (Agent, GO (Theme, TO (IN (DRAWER)))). A rather awkward but faithful paraphrase would be 'an Agent causes a Theme to move along a Path that ends inside a drawer'. More formal models will be offered in Section 5.2.

- $\quad \operatorname{AT}(Z)$ denotes a Place defined by its argument Z, without the implication that the Theme is "inside" the object, like when we say The car stopped at the lights. The meaning of a verb like enramar ('to put branches somewhere, for decoration or for shade') can be semi-formally modeled as CAUS (Agent, GO (BRANCHES, TO (AT (Place)))). 
- $\mathrm{ON}(\mathrm{Z})$ denotes a Place, defined as any point along the surface of the object $\mathrm{Z}$. It can be marked with the feature [+dist], following Jackendoff ${ }^{5}$, to indicate that multiple, similar objects are distributed along the surface. See below the example of embaldosar ('to cover the floor with tiles').

- $\operatorname{ALONG}(Z)$ denotes a Path, defined by the object $Z$. The meaning of a verb like encarrilar ('to make something go along a lane') can be semi-formally modeled as CAUS (Agent, GO (Theme, ALONG (LANE))).

- $\operatorname{AROUND}(Z)$, introduced by us for the purposes of this analysis, denotes a Place, defined as the surface length of the object $Z$. The meaning of a verb like encabuyar ('to twine something with rope') can be semi-formally modeled as CAUS (Agent, GO (ROPE, AROUND (Object))).

The function MOVE $(\mathrm{Y}, \mathrm{Z})$ denotes a movement Event without change of location, as opposed to GO. Its first argument $\mathrm{Y}$ takes the role of Theme, and the second argument $\mathrm{Z}$ usually denotes a Position (relationship among the parts of the object Y) or Manner of movement. The meaning of a verb like enderezar ('to straighten') can be semi-formally modeled as CAUS (Agent, MOVE (Theme, STRAIGHT)).

The function ORIENT $(Y, Z)$ denotes a State in which the Theme $Y$ is oriented toward a Path Z, defined by the function TOWARD (Y), whose argument is a Path. The meaning of a verb like enfocar ('to focus, to direct a light at an object') can be semi-formally modeled as CAUS (Agent, ORIENT (LIGHT, TOWARD (Object))).

The function BE $(Y, Z)$ denotes a State in which the Theme $\mathrm{Y}$ is ascribed $\mathrm{Z}$. When this function is the argument of the aspectual function INC (F), as in inchoative, the whole denotes the beginning of the State. The meaning of a verb like enceguecer ('to blind') can be semiformally modeled as CAUS (Agent, INC (BE (Theme, BLIND))).

The function PLUR (Y) denotes simply the plurality of the Object that is its argument, that is, multiple objects on the same kind. See below the example of embaldosar ('to cover the floor with tiles').

The function WITH (Y) denotes a Means, defined by the instrument Object that is its argument, and it denotes the instrument by means of which the Agent achieves the causation event. The meaning of a verb like encabestrar ('to lead with a halter, especially a bull') can be semi-formally modeled as CAUS (Agent, GO (BULL, ALONG (Path)), WITH (HALTER)).

For the present analysis, we have furthermore introduced the functions LIKE (Y) and EXP $(\mathrm{Y}, \mathrm{Z})$. The former is used to denote a Property or a Shape with which a resemblance relationship is established. The meaning of a verb like enacerar ('to make something like 
steel') can be semi-formally modeled as CAUS (Agent, INC (BE (Object, LIKE (STEEL)))). The latter typically denotes a State, like BE, in which the Theme Y experiences the Mental or Physical State Z. The meaning of a verb like encolerizar ('to enrage someone') can be semiformally modeled as CAUS (Agent, INC (EXP (Theme, RAGE))). For intentional mental states (directed at an object), the argument $\mathrm{Z}$ takes itself an argument denoting the Object of said mental state. The meaning of a verb like enamorar ('to make someone fall in love') can be semi-formally modeled as CAUS (Agent, INC (EXP (Theme, LOVE (Object)))).

Many of these functions can be metaphorically relativized to various semantic fields. Thus, GO is typically spatial, but it can have a version $\mathrm{GO}_{\text {Pos }}$ for the semantic field of possession, where it denotes not a physical movement, but a transference. In the same manner, spatial $\mathrm{BE}$ has a version $\mathrm{BE}_{\mathrm{Asc}}$ for the semantic field of ascription, where properties are ascribed to Objects. This metaphorical co-opting of spatial concepts to structure more abstract semantic domains is widely documented in the literature ${ }^{6}$ as a defining, pervasive feature of human thought and language.

The features of Contact (C) and Attachment (A) (which always implies Contact) can mark functions such as AT or AROUND to indicate that the Theme touches the surface of the Object or, additionally, that it is attached to it. In these cases, following Jackendoff ${ }^{7}$, the features also mark the functions $\mathrm{GO}$ or BE of which the former are the arguments.

We will give two examples that illustrate the combinatorial capacity of these functions to build semantic structures: the verbs embaldosar ('to cover the floor with tiles') and enacerar ('to make something like steel').

- embaldosar - [Event CAUS ([object $\underline{\mathrm{X}}]$, [Event GO $\mathrm{GO}_{\mathrm{C}, \mathrm{A}}([$ object PLUR $([$ object N])], [Path TO ([Place ON $\mathrm{O}_{[+\mathrm{DIST}], \mathrm{C}, \mathrm{A}}([$ object FLOOR])])])])]

- enacerar - [Event CAUS ([object $\underline{X}]$, [Event INC [State BE Asc $([$ object $\underline{Y}]$, [Property LIKE $([$ object $\mathrm{N}])])]])]$

Note that the base of the derived verb ( $\mathrm{N}$ in both cases) is part of the semantic structure. This is shorthand for the semantic structure of the base ( $\mathrm{N}$ or Adj), whatever it happens to be.

\section{Description of the corpus}

Our results are based on a corpus of 374 verbs, many of which have more than one meaning. A sample of the corpus can be found in the appendix. The lexicographical definitions (and the etymological information presented below) were taken from the Dictionary of Spanish Usage Maria Moliner (2008), although we occasionally consulted other lexicographical sources as support. 
Two main inclusion criteria were followed: (a) the verb had to be formed by derivation with the prefix en-; and (b) the verb had to have at least one causative meaning. We left out $e n-$ verbs whose derivation process was synchronically opaque, because either

- they were formed in Latin from a base inexistent in modern Spanish, like encrasar, 'to thicken' (Lat. incrassāre, 'to thicken'), or engañar, 'to deceive' (from the vulgar Latin ingannāre, 'to mock');

- the supposed prefix en-is actually an altered form of a previous word, like enjambrar, 'to put a swarm of bees inside a hive' (Lat. examināre), or enjebar, 'to whitewash a wall' (Lat. exalbāre);

- they are more recent loans from other languages, like embarazar, 'to get someone pregnant' (from the Portuguese or Leonese embaraçar, from baraça, lasso), encaramar, 'to put on a high place' (Andalusian Arabic karáma), enfrascarse, 'to immerse oneself in an activity' (Italian infrascarsi), endosar, 'to foist something to someone' (French endosser), encriptar (English encrypt); or

- their segmentation does not produce an existing base in modern Spanish, like endilgar ('to foist something on someone'), enfunchar ('to annoy someone'), engendrar ('to engender').

We also left out verb-based verbs with a superfluous en-prefix (like encubrir, 'to cover up'), archaic verbs, and some uninformative regionalisms.

\section{Methodology}

The technique of lexicographical definition analysis was used, first, to determine which meanings of the verbs were causative. These were the meanings included in the corpus.

The segmentation technique was used to establish the various morphological and phonological schemas. In the case of morphological schemas, this technique was also used to determine the base (noun or adjective) from which the verb had been derived.

The semantic structure of the units was modeled with the tools of Conceptual Semantics, that is, semantic functions with predicate-argument structure. Once again, we used the technique of lexicographical definition analysis to determine whether the units had idiosyncratic meanings (e.g. incorporated arguments).

The method of immediate constituent analysis was used to establish the various syntactic schemas to which the units conformed.

\section{Results and discussion}


The verbs in the corpus all conform to a single general morphological schema:

$$
\text { [v } e n-\{\underline{N}, \underline{\operatorname{Adj}}\}-\text { Suff] }
$$

(The braces $(\{\})$ indicate a choice between the two elements. The underlining indicates here the "open" elements, that is, the variables that are replaced by lexical units.)

This general schema is realized in 5 particular schemas. We list them here from most frequent to least frequent in the corpus.

1. [v en $-\underline{\mathrm{N}}-a r$ ], as in embaldosar ('to tile', from baldosa, 'tile'), embarrar ('to cover with mud', from barro, 'mud'), or embarrilar ('to put in barrels', from barril, 'barrel')

2. [v en- $\underline{A d j}$ - ecer], as in encarecer ('to make more expensive', from caro, 'expensive'), enceguecer ('to blind', from ciego, 'blind'), or endurecer ('to harden', from duro, 'hard')

3. [v en - Adj-ar], as in enfriar ('to chill, cool, make cold', from frio, 'cold'), engordar ('to fatten', from gordo, 'fat'), or engrandar ('to enlarge', from grande, 'big, large')

4. [v en $-\underline{\mathrm{N}}-$ ecer], as in enfebrecer ('to cause to have a fever', from fiebre, 'fever') or enfurecer ('to anger', from furia, 'anger')

5. [v en $-\underline{\mathrm{N}}$-izar], as in encenizar ('to cover with ash', from ceniza, 'ash') or encolerizar ('to enrage', from cólera, 'rage')

Among these, the only truly productive schemas in modern Spanish seem to be the first two: [v en $-\underline{\mathrm{N}}-a r]$ and $[\mathrm{v} e n-\underline{\mathrm{Adj}}-$ ecer]. These two schemas thus have a generative function, i.e. they work as "moulds" from which to coin new verbs of this kind. The others have a relational function: they motivate existing verbs, making the relationship between meaning and form less arbitrary ${ }^{8}$.

In the following sections, we will analyse separately what happens with the phonological, semantic, and syntactic components, and the interactions between them.

\subsection{Phonology}

All the verbs in the corpus conform to a single phonological schema:

$$
[\omega / \mathrm{eN} / 1 / \ldots / 2 / \ldots / 3]_{4}
$$

The prosodic word $(\omega)$ is formed by three phonological chains $(/ /)$ that can be linked to semantic and syntactic constituents. They are marked here with subscripts, which we will reuse below. 
Because there is no isomorphism between morphological and phonological constituents, morphemes do not necessarily correspond to syllables or prosodic words ${ }^{9}$. The prefix en-and the verbal suffixes (-ar, -ecer, -izar) are cohering affixes, i.e. they form a prosodic unit with the base they attach to, and the syllabification pattern ignores the morphological boundaries. This means that morphosyntactic structure is invisible to the part of phonology that deals with syllable structure. As an example, consider the verb enamorar ('to make someone fall in

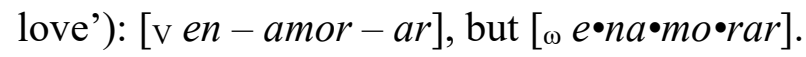

A similar thing happens with primary and secondary stress assignment during syllabification. The prefix en-is atonic, but it is systematically stressed in words with an uneven number of syllables: enacerar ${ }^{10}$ ('to make something like steel'), but enarcar ('to arch'); calabozo ('jail cell'), but encalabozar ('to put someone in a jail cell'). At the same time, the base loses its original stress to the verbal suffix, which is always stressed in Spanish: astil ('haft', a kind of handle), but enastilar ('to put a haft on a tool'); ca $\underline{\underline{\text { brón }}}$ (in Cuban usage, 'pissed off'), pero encabronar ('to piss someone off'). As a result of these two processes, all verbs formed with the prefix en-are, prosodically, sequences of iambic feet.

But maybe the largest variety of phonological activity is found in the changes undergone by the base (N, Adj) when it is incorporated into the verb. Although there is a considerable amount of idiosyncratic behaviors, it is possible to identify some general patterns of phonological variation (beyond stress reassignment):

- Deletion of final vowel in unstressed syllable (aceite ('oil') $\rightarrow$ enaceitar ('to put oil on something'), acero ('steel') $\rightarrow$ enacerar ('to make something like steel'), cóler $\underline{a}$ ('rage') $\rightarrow$ encolerizar ('to enrage someone'))

- Deletion of final diphthong in unstressed syllable, when the diphthong vowel is different from the thematic vowel (furia 'anger' $\rightarrow$ enfurecer ('to anger someone')), but not when the vowels are the same (furia $\rightarrow$ enfuriar ('to anger someone')).

- Reduction of rising diphthong [je] and [we] in unstressed syllable (ciego ('blind') $\rightarrow$ enceguecer ('to blind someone'), tierra ('earth') $\rightarrow$ enterrar ('to bury'), cueva ('cave') $\rightarrow$ encovar ('to put in a cave')). However, we find chueco ('crooked') $\rightarrow$ enchuecar ('to bend, warp, twist') y hiel ('bile') $\rightarrow$ enhielar ('to mix something with bile'), among others.

- Diphthongization of stressed hiatus (hastío ("tedium') $\rightarrow$ enhastiar ('to bore

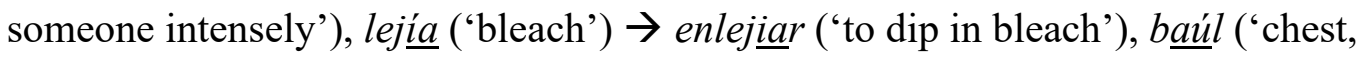
trunk') $\rightarrow$ embaular ('to put something in a chest or trunk')) 
- No change, with final consonant in CVC syllable (a $\underline{\text { mor }}$ ('love') $\rightarrow$ enamorar ('to make someone fall in love'), árbol ('tree') $\rightarrow$ enarbolar ('to hoist, to brandish'), cajón ('drawer') $\rightarrow$ encajonar ('to put something in drawer'))

There are other interesting, although far less frequent changes, such as:

- Insertion of phonestheme (agua ('water') $\rightarrow$ enaguachar ('to water the earth excessively') / enaguazar (same), lodo ('mud') $\rightarrow$ enlodazar ('to get something dirty with mud'))

- Appearance of a linking consonant (corsé $\rightarrow$ encorsetar ('to put a corset on someone')). It may be orthographically motivated (from Fr. corset), but it can be the same consonant found in cafetal ('coffee plantation'), cafeteria ('coffee shop'), tetera ('teapot'), where the bases (café, té) end in a stressed /e/, like corsé.

It is also worth mentioning that the prefix en-itself undergoes changes, to wit, its realization as different allomorphs by assimilation: dentalization (endentar), velarization (engavetar), labialization (enmascarar).

These variations (except, maybe, phonestheme insertion) are the result of rules, with varying degrees of productivity, operating in the syntax-phonology interface, as their application depends on the combination of lexical units, in this case morphemes. On the other hand, the analysis did not show any notable interactions between phonology and semantics. In this interface, we can only point out the cases of phonestheme insertion, where a phonological segment is linked to evaluative semantic contents (in the corpus, negative connotation).

\subsection{Semantics}

The verbs in the corpus all conform to a single general semantic schema:

$$
\text { [Event CAUS ([object Agent], [F (Theme), ...])] }
$$

All the analysed verbs denote events of causation. The function CAUS takes, in principle, two arguments: the Agent of the causation, belonging to the ontological class Object (usually human); and a second function (F) with its Theme (or Patient) argument. The ellipsis (...) stands for other possible arguments, the selection of which depends on this second function.

Depending on this second function and its arguments, this schema is realized as 9 specific semantic schemas, on a first level of specificity. We will present here what we have called "transparent" semantic schemas, in which the meaning of the base is part of the semantic structure. Other units in the corpus correspond to "opaque" semantic schemas, in which the meaning of base is not part of the semantic structure. These are not included here. As will be seen, some polysemous verbs correspond to more than one semantic schema. 
1. Change of place

a. Putting something inside something

i. Base is Theme

1. Theme is Substance: [Event CAUS ([Object $\underline{X}]$, [Event GO ([Substance $\mathrm{N}]$, [Path TO ([Place IN ([object $\underline{\mathrm{Y}}])])])])]$ - enaguachar ('to water the earth excessively'), enaguar (same), endrogar ('to administer drugs to someone'), enguatar ('to pad'), among others.

2. Theme is Object: [Event CAUS ([object $\underline{X}]$, [Event GO ([object $\mathrm{N}]$, [Path TO ([Place IN ([object $\underline{Y}])])])])]$ - endemoniar ('to put demons inside someone'), endiablar (same), among others.

ii. Base is Goal

1. Theme is individual Object / Individual Goal: [Event CAUS ([Object $\underline{\mathrm{X}}]$, [Event GO ([object $\underline{\mathrm{Y}}]$, [Path TO ([Place IN ([object N])])])])] - embaular ('to put in a chest or trunk'), encajonar ('to put in a drawer'), encalabozar ('to put someone in a jail cell'), encapsular ('to put in a capsule'), encarcelar ('to put someone in prison'), among others.

2. Theme is several similar Objects / Individual Goal: [Event CAUS ([object $\underline{\mathrm{X}}]$, [Event GO ([object PLUR ([object $\underline{\mathrm{Y}}])]$, [Path TO ([Place IN ([object $\mathrm{N}])])])])]$ - embarrilar ('to put in barrels'), encantarar ('to put ballots in a box'), encorachar ('to put in a leather sack, especially merchandises, for transportation'), among others.

3. Theme is several similar Objects / Several similar Goals: [Event CAUS ([object $\underline{X}]$, [Event GO ([object PLUR ([object $\underline{Y}])]$, [Path TO ([Place IN ([object PLUR ([object N])])])])])] — encasillar ('to put in pigeonholes'), encostalar ('to put in sacks'), enlatar ('to put in cans'), among others.

4. Theme is Substance / Individual Goal: [Event CAUS ([object $\underline{X}$, [Event GO ([Substance Y $]$, [Path TO ([Place IN ([ Object N])])])])] — embarrilar ('to put in a barrel').

5. Theme is Substance / Several similar Goals: [Event CAUS ([object $\underline{\mathrm{X}}]$, [Event GO ([Substance $\underline{\mathrm{Y}}]$, [Path TO ([Place IN ([object PLUR ([Object 
N])])])])])] — embarrilar ('to put in barrels'), embotellar ('to put in bottles'), enlatar ('to put in cans'), among others.

6. Goal is Substance: [Event CAUS ([Object $\underline{X}$ ], [Event GO ([object $\underline{Y}]$, [Path TO ([Place IN ([Substance N])])])])] - enlejiar ('to dip in bleach'), enterrar ('to bury').

b. Putting something on something

i. Base is Theme

1. Individual Object: [Event CAUS ([object $\underline{\mathrm{X}}]$, [Event GO ([object $\mathrm{N}]$, $[$ Path TO $([$ Place ON ([object $\underline{\mathrm{Y}}])])])])]$ - encamisar ('to put a shirt on someone'), encaperuzar ('to put a hood on someone'), encorbatar ('to put a tie on someone'), encorsetar ('to put a corset on someone'), enmantar ('to cover with a blanket'), enmascarar ('to cover someone's face with a mask'), among others.

2. Several similar Objects: [Event CAUS ([object $\underline{X}]$, [Event GO ([object PLUR ([object N])], [Path TO ([Place $\mathrm{ON}_{[+ \text {DIST }]}([$ object $\left.\left.\left.\left.\left.\left.\left.\underline{Y}])\right]\right)\right]\right)\right]\right)\right]-$ embanderar ('to adorn with flags'), encartonar ('to cover with pieces of cardboard'), encascabelar ('to adorn with bells'), enchapar ('to cover with veneers'), enflorar ('to adorn with flowers'), among others.

3. Spreading a Substance: [Event CAUS ([object $\underline{\mathrm{X}}]$, [Event GO ([Substance N], [Path TO ([Place ON ([object $\underline{\mathrm{Y}}])])])])]$ - embarrar ('to cover with mud'), enaceitar ('to cover with oil'), enalmagrar ('to cover with ocher'), enarenar ('to cover with sand'), encalar ('to cover with lime'), encauchar ('to cover with rubber'), encerar ('to cover with wax'), among others.

c. Attaching something to something

i. Base is Theme: [Event CAUS ([object $\underline{X}]$, [Event INC [State BE $\mathrm{B}_{\mathrm{C}, \mathrm{A}}([$ object $\mathrm{N}$ ], [Place $\operatorname{AT}_{\mathrm{C}, \mathrm{A}}([$ object $\left.\left.\left.\left.\left.\left.\underline{\mathrm{Y}}])\right]\right)\right]\right]\right)\right]$ - enrayar ('to put spokes on a wheel').

ii. Base is Place: [Event CAUS ([object $\underline{X}$ ], [Event INC [state BE $E_{C, A}([$ object $\underline{Y}]$, [Place $\operatorname{AT}_{C, A}([$ object $\left.\left.\left.\left.\left.\left.\mathrm{N}])\right]\right)\right]\right]\right)\right]$ - encepar ('to put in a clamp'), enquiciar ('to put in a jamb, especially a door or window'), among others.

iii. Base is Instrument: [Event CAUS ([object $\underline{X}]$, [Event INC [state BE $\mathrm{C}_{\mathrm{C}, \mathrm{A}}([$ object $\underline{\mathrm{Y}}]$, [Place $\mathrm{AT}_{\mathrm{C}, \mathrm{A}}([$ object $\left.\left.\left.\left.\underline{\mathrm{Z}}])\right]\right)\right]\right]$, [Means WITH (object $\left.\left.\left.\left.\mathrm{N}\right)\right]\right)\right]$ - enganchar 
('to attach with a hook'), engoznar ('to attach with a hinge'),

enmaromar ('to attach with a special kind of rope'), among others.

d. Putting something around something

i. With contact

1. Theme is individual Object: [Event CAUS ([object $\underline{X}$ ], [Event $\mathrm{GO}_{\mathrm{C}}$ $\left([\right.$ object $\mathrm{N}],\left[\right.$ Path TO $\left(\left[\right.\right.$ place $\operatorname{AROUND}_{\mathrm{C}}([$ object $\left.\left.\left.\left.\left.\left.\left.\underline{\mathrm{Y}}])\right]\right)\right]\right)\right]\right)\right]-$ encabuyar ('to twine with rope'), encorar ('to cover with leather'), encordar ('to twine with a string'), encordelar ('to twine with a cord'), among others.

2. Theme is several similar Objects: [Event CAUS ([object $\underline{X}$ ], [Event $\mathrm{GO}_{\mathrm{C}}([$ object PLUR ([object N])], [Path TO ([Place AROUNDC $([$ object Y])])])])] - encordonar ('to twine with cords or strings').

ii. With contact and attachment

1. Theme is individual Object: [Event $\mathrm{CAUS}$ ([object $\underline{\mathrm{X}}]$, [Event $\mathrm{GO}_{\mathrm{C}, \mathrm{A}}$ $([$ object $\mathrm{N}],[$ Path TO $([$ place AROUND, $\mathrm{A}([$ object $\underline{\mathrm{Y}}])])])])]-$ enlazar ('to attach with a bow').

iii. Without contact: [Event CAUS ([Object $\underline{X}],[$ Event GO ([Object N], [Path TO ([Place AROUND ([Object $\underline{\mathrm{Y}}])])])])]$ - encambronar ('to surround a field with buckthorns or brambles').

e. Putting something at some place

i. Base is Theme

1. Several similar objects: [Evento CAUS ([objeto $\underline{X}$ ], [Evento GO ([objeto PLUR ([objeto N])], [Camino A ([Lugar AT [+DIST] $_{\text {([objeto }}$ Y])])])])] - enramar ('to put branches somewhere, for decoration or for shade')

2. Change of position

a. Relationship among the parts of an individual Object: [Event CAUS ([object $\underline{X}$, [Event MOVE ([object $\underline{\mathrm{Y}}]$, [Position AT ([object N])])])] — enfielar ('to align the scales to the needle').

3. Leading

a. Without Instrument: [Event CAUS ([object $\underline{X}]$, [Event GO ([object $\underline{Y}]$, [Path ALONG $([$ object $\mathrm{N}])])])$ ] - encallejonar ('to make something go through an alley'), encaminar ('to make something go along a path'), encarrilar ('to make something go along a lane'), among others. 
b. With Instrument: [Event CAUS ([Object $\underline{X}$ ], [Event GO ([ Object $\underline{Y}]$, [Path ALONG ([object $\underline{\text { PATH}}])])],[$ Means WITH $([$ object $\mathrm{N}])])]$ — encabestrar ('to lead with a halter, especially a bull').

4. Change of properties

a. Transformation

i. Patient is Object: [Event $\mathrm{CAUS}\left([\right.$ object $\underline{\mathrm{X}}],\left[\right.$ Event $\mathrm{INC}\left[\right.$ State BE $\mathrm{BEsc}_{\mathrm{Asc}}([$ object $\underline{\mathrm{Y}}$ ], [Property $\mathrm{Adj} / \mathrm{N}])]]$ )] — enangostar ('to make narrow'), encanijar ('to make weak and rickety'), encarecer ('to make more expensive'), enceguecer ('to blind'), endulzar ('to sweeten'), enlustrecer ('to make shiny, glossy'), among others.

ii. Patient is Situation: [Event CAUS ([object $\underline{X}]$, [Event INC [State BE $\mathrm{Asc}_{\mathrm{Asc}}$ ([Situation $\underline{Y}],[$ Property Adj])]])] — endulzar ('to sweeten, soften').

b. Likening: [Event CAUS ([object $\underline{X}]$, [Event INC [state BE Asc ([object $\underline{Y}]$, [Property LIKE ([object $\mathrm{N}])])]])]$ — enacerar ('to make something like steel'), encarnar ('to make something like flesh'), endiosar ('to make someone like a god in status and treatment'), etc.

5. Change of shape

a. Transformation: [Event CAUS ([object $\underline{X}]$, [Event INC [State BE ([object $\underline{Y}]$, [Shape $\mathrm{N}]$ )]])] - enarcar ('to arch'), enchuecar ('to bend, warp, twist').

b. Likening: [Event CAUS ([object $\underline{X}$ ], [Event INC [State BE ([object $\underline{Y}]$, [Shape LIKE $([$ object $\mathrm{N}])])]])]$ - encanutar ('to make something like a tube'), engarabatar ('to make something like a hook or grapnel'), among others.

6. Change of orientation

a. Individual Theme: [Event CAUS ([object $\underline{X}]$, [State ORIENT ([object N], [Path TOWARD ([object $\underline{Y}])])])]$ - enfocar ('to focus, to direct a light at an object').

b. Two Themes: [Event [Event CAUS ([Object $\underline{X}]$, [State ORIENT ([object $\underline{Y}]$, [Path TOWARD ([object $\underline{Z}])])])]$; [Event CAUS ([object X], [State ORIENT ([object Z], [Path TOWARD ([object Y])])])]] - encarar ('to bring two things face to face'), enfrentar (same).

7. Constitution (a Substance or several similar Objects constitute a single distinct Object)

a. Patient is several similar Objects: [Event $\mathrm{CAUS}$ ([object $\underline{\mathrm{X}}$ ], [Event $\mathrm{INC}$ [State BE $\mathrm{Asc}_{\mathrm{Asc}}$ ([object PLUR ([object $\underline{\mathrm{Y}}])]$, [object PLUR ([object N])])]])] — enfardar ('to make 
up into a bale'), enfardelar (same), enlegajar ('to make papers up into a tied up stack').

b. Patient is Substance: [Event CAUS ([object $\underline{\mathrm{X}}]$, [Event $\mathrm{INC}$ [State BEAsc ([Substance $\underline{\mathrm{Y}}]$, [object PLUR ([object N])])]])] — engavillar ('to make the ripe grain up in sheaves').

8. Transference

a. Possession of individual Object: [Event CAUS ([object $\underline{X}$ ], [Event GOPos ([object $N]$, [Path TO ([object $\underline{Y}])])])]$ — enfeudar ('to give someone a fiefdom').

9. Causation of experience

a. Intentional mental state

i. Object is Agent: [Event CAUS ([Object $\underline{X}$ ], [Event INC [State EXP ([Object $\underline{Y}]$, [MState $\mathrm{N}([$ object $\mathrm{X}])])]])]$ - enamorar ('to make someone fall in love'), encelar ('to make someone jealous'), enfurecer ('to anger someone'), enorgullecer ('to make someone proud'), among others.

ii. Object is not Agent: [Event CAUS ([object $\underline{X}]$, [Event INC [state EXP ([object $\underline{\mathrm{Y}}]$, [MState $\mathrm{N}([\mathrm{object} \underline{\mathrm{Z}}])])]])]$ — encariñar ('to make someone fond of something'), enfervorecer ('to make someone passionate or enthusiastic about something'), enfervorizar (same).

b. Non-intentional mental state: [Event CAUS ([object $\underline{X}]$, [Event INC [State EXP ([object Y], [MState N])]])] — encalmar ('to calm someone'), encolerizar ('to enrage someone'), encorajar ('to give someone courage'), encorajinar ('to make someone furious'), encuitar ('to trouble someone'), enhastiar ('to bore someone intensely'), among others.

c. Physical state: [Event CAUS ([object $\underline{X}]$, [Event INC [State EXP ([object $\underline{Y}]$, [PhState $\mathrm{N}]$ )]])] - enfebrecer ('to cause to have a fever').

What we take out of this considerable semantic diversity is that there is no uniformity that allows us to systematically predict the meaning of the derived verb. There are, however, some regularities. Thus, for instance,

- when the base is a $\mathrm{N}$ denoting an Object with a defined interior space (a container such as botella ('bottle') or barril ('barrel'), but also baúl ('chest'), gaveta ('drawer'), etc.), the meaning of the causative verb will be 'to put NP inside $\mathrm{N}_{\text {Goal }}$ ' (schemas 1.a.ii.1-5); 
- when the base is a $\mathrm{N}$ denoting a Path (callejón ('alley'), camino ('path'), carril ('lane')), the meaning of the verb will be 'to make NP travel along $\mathrm{N}_{\text {Path }}$ ' (schema 3.a);

- when the base is an Adj or a $\mathrm{N}$ denoting a Property (angosto ('narrow'), caro ('expensive'), ciego ('blind'), dulce ('sweet'), lustre ('luster')), the meaning of the verb will be 'to make NP be (more) Adjproperty / have (more) NProperty' (schema 4.a);

- when the base is a $\mathrm{N}$ denoting a mental or physical State (amor ('love'), furia ('anger'), orgullo ('pride'), cariño ('fondness'), fiebre ('fever'), etc.), the meaning of the verb will be 'to make NP experience / begin to experience $\mathrm{N}_{\text {State }}$ ' (schema 9).

\subsection{Syntax}

The units in the corpus all conform to a single syntactic schema:

$$
\text { [s NPX, [VP V (NPY) ...]] }
$$

The sentences built around these verbs have, at least, a subject NP and a direct object NP. Now, many of these verbs have intransitive pronominal forms, with only a subject NP, like embarcarse ('to board or embark'), enamorarse ('to fall in love'), encabronarse ('to get pissed off'), encalmarse ('to calm down'), encaminarse ('to head or set off toward something'). As can be seen from their English glosses, these forms are not causative, but inchoative, and they will be discussed at the end of this section.

Depending on the semantic schemas we saw above, this general syntactic schema is realized in 3 specific syntactic schemas, on a first level of specificity.

The first one is the standard transitive schema:

$$
\text { [S NPX, [VP V (NPY)]] }
$$

where the sentence is built only with a subject NP and a direct object NP.

This object NP can carry the roles of Theme (embarcar ('to load onto a ship'), embaular ('to put in a chest or trunk'), encajetillar ('to put (cigarettes) in packs'), encamar ('to put someone in bed'), encaminar ('to make something go along a path'), encarcelar ('to put in prison'), among others), Goal (embaldosar ('to cover the floor with tiles'), embalsamar ('to embalm'), enaceitar ('to cover with oil'), encenizar ('to cover with ash'), among others), Patient (enangostar ('to make narrow'), enarcar ('to arch'), encarecer ('to make more expensive'), enceguecer ('to blind'), among others), or Experiencer (enamorar ('to make someone fall in love'), encelar ('to make someone jealous'), encolerizar ('to enrage someone'), encorajar ('to give someone courage'), among others). 
When the object NP refers to a human, it is introduced by the preposition $a$ ('to'). This is not a different syntactic schema, but a case of differential object marking (DOM), whereby Spanish distinguishes human objects from non-human (or inanimate) ones ${ }^{11}$. This is also true for all following schemas.

The second specific schema is the transitive schema with a prepositional phrase:

$$
\text { [s NPX, [VP V (NPY) [PP P (NPz)]] }
$$

Depending on the preposition heading this PP, we can identify 4 more specific schemas:

- Transitive + PP-con ('with'): [s NPX, [vP V (NPy) [PP con $(\mathbf{N P z})]$ - enamorar ('to make someone fall in love with someone'), encubertar ('to cover with cloths or the like'), engrasar ('to cover with oil or the like'), among others. $\mathrm{NP}_{\mathrm{Z}}$ can instantiate the Theme, the Instrument, or the Object of an intentional mental state.

- Transitive + PP-de ('of'): [s NPX, [VP V (NPy) [PP de (NPz)] - embarrar ('to cover with mud or other such substance'), among others. $\mathrm{NP}_{\mathrm{z}}$ typically instantiates the Theme.

- Transitive + PP-en ('in'): [s NPX, [VP V (NPy) [PP en (NPz)] - embarcar ('to load onto a ship, plane, train'), encantarar ('to put ballots in a box'), encovar ('to put in a cave or similar location'), among others. $\mathrm{NP}_{\mathrm{Z}}$ typically instantiates the Goal.

- Transitive + PP-a ('to'): [s NPx, [vP V (NPy) [PP a (NPz)] - encasquetar ('to put a hat on someone'. $\mathrm{NP}_{\mathrm{Z}}$ typically instantiates the Goal.

Finally, the third schema is the double transitive schema:

$$
\text { [s NPx, [vP V ([sN NPy } y \text { NPy])]] }
$$

where the sentence has a subject NP and two coordinated direct object NPs (with the conjunction $y$, 'and') that carry the same semantic role. It is not a frequent schema, and the corpus only includes two cases: the verbs encarar and enfrentar ('to bring two things face to face'), very close in meaning, which correspond to a schema like [s NP, [VP V ([NP NPTheme1 $y$ NPTheme2])]].

The most noteworthy thing we find when analysing the interaction of the semantic and syntactic components in these verbs, is the matter of redundancies. The corpus includes many verbs whose semantic structure contains only one open variable (the Agent); the rest are filled with material already incorporated into the semantic argument structure (Theme, Goal, etc.). In other words, this material is already part of the verb's meaning. According to Jackendoff ${ }^{12}$, one of these closed variables can be instantiated in the syntax without it producing a redundancy, but only if the phrase instantiating the variable expands on the information 
already incorporated. Thus, for example, *bottling the wine in bottles is redundant, but bottling the wine in plastic bottles is not, because the NP plastic bottles provides additional information, to wit, the material.

However, this is not exactly what we observe in the Spanish corpus. In verbs with incorporated direct objects like enaguazar ('to water the earth excessively', and only 'the earth'), enalbardar ('to put packsaddles on a horse', and only 'on a horse'), enastilar ('to put a haft (a kind of handle) on a tool', and only 'on a tool'), encajetillar ('to put cigarettes in a pack', and only 'cigarettes'), encarpetar ('to put papers in folders', and only 'papers'), encorchar ('to cork a bottle', and only 'a bottle'), and many others, we see that this direct object can be instantiated in the syntax without providing additional information and without producing redundancies: enaguazar la tierra ('to water the earth excessively'), encarpetar los papeles ('to put the papers in folders'), encorchar una botella ('to cork a bottle') are all perfectly grammatical.

Redundancies are produced, however, when trying to instantiate, in the syntactic argument structure, the argument already filled by the base of the derived verb: *enaguazar la tierra de agua ('to water the earth with water') (Theme), *encarpetar los papeles en una carpeta (lit. 'to folder the papers in a folder') (Goal), *encorchar una botella con un corcho ('to cork a bottle with a cork') (Theme). But the other semantic material (the incorporated direct object) should also produce redundancies: the only thing one can enaguazar is the earth, as the only thing one can cork is a bottle. How can we explain this?

Our hypothesis is that there are two constraints of the syntax-semantics interface that must be satisfied simultaneously: (1) the Theme role in the semantic structure must be realized in some syntactic argument; and (2) causative verbs must have a direct object. The verbs in which the base carries the Theme role (like encorchar and enaguazar) violate the second constraint if they fail to take a direct object (as in *Juan encorchó, '*John corked'), and the only semantic role left is Goal, although it is already incorporated ('bottle' and 'earth', respectively). The verbs in which the base carries the Goal role (like encajetillar, 'to put cigarettes in a pack', or encarpetar, 'to put papers in folders') violate both constraints if they fail to take a direct object carrying the Theme role (as in *Juan encarpetó, '*John put in folders'), although it too is already incorporated ('cigarettes' and 'papers', respectively). This hypothesis, proposed here in an arguably ad hoc fashion, awaits independent verification.

Systematic violations of these constraints have, however, become lexicalized as part of absolute constructions. Take, for instance, the case of encestar (lit. 'to put something in a basket', Sp. cesta). When used as a basketball term, it means 'to score' (lit. 'to put the 
basketball in the basket'), and it is used in an absolute way, as in Juan encestó ('John scored'). So this has the flavor of the violable constraints of Optimality Theory or Jackendoff's preference rules. ${ }^{13}$

Other cases do conform to Jackendoff's generalization perfectly, but they do so in a rather special way: by way of paradigmatic lexical relationships. Thus, *encasquetarle un casquete a alguien en la cabeza ( $\approx$ 'to hat someone with a hat') is redundant, but encasquetarle un sombrero en la cabeza a alguien is not (an English approximation would be 'to hat someone with beret'). This is because sombrero ('hat'), being a hyponym of casquete ('any piece of clothing covering the top of the head'), provides additional information (it is more specific). The same thing happens with encubertar un caballo con una armadura ('to cover a horse with an armor', where 'an armor' is a kind of cover) and with engrasar la rueda con aceite ('to oil the wheel with grease', where 'grease' is a kind of oil). A special case is embarcar las mercancias en el avión ('to load the merchandise on the plane', but an English approximation would be 'to ship the merchandise by plane'), where avión ('plane') is not a hyponym, but a cohyponym of barco ('ship, boat'): they are both means of transportation.

Moving on from redundancies, some verbs in the corpus have pronominal ("reflexive") variants (enamorarse ('to fall in love'), encarecerse ('to become more expensive'), among others). In general, the pronominal variants of these verbs are not causative (or even selfcausative, bar some exceptions), but inchoative. As a result, as Marín \& McNally argue when discussing Spanish reflexive psychological verbs (although the generalization is valid for other kinds of verbs), these verbs "denote the beginning of the state they are associated to, without reference to the change that brings about the state" 14 (our translation). If that "change that brings about the state" is ignored, we are not allowed to speak of causation.

We forgo discussing the contribution of the se morpheme to the semantic structure of these verbs. We will only point out that, if there really is no causation, the se morpheme cannot be a direct object coreferent with an Agent subject, which it is in truly reflexive verbs. In pseudo-reflexives like these, the se morpheme apparently "blocks" the causative fragment of the semantic structure, which includes the Agent or Causer argument, leaving only one free argument to occupy the subject position (Theme, Experiencer, Goal, etc.) and the piece of semantic structure corresponding to [Event $\operatorname{INC}\left[\right.$ state $\left.\left.\mathrm{BE}_{\mathrm{Asc}}(\ldots)\right]\right]$ or [Event $\mathrm{INC}[$ state $\operatorname{EXP}(\ldots)]$, which accounts for their inchoative interpretation.

Having discussed the phonological, semantic, and syntactic components of the analysed units, as well as the interactions between them, we can model the morphological schemas by 
bringing together the three components into an interface rule that accounts for the lexical representation of the causative prefix en-:

Semantics: $\quad\left[\text { Event } \operatorname{CAUS}\left(\left[\text { object } \underline{X}_{5}\right],\left[F \ldots\left|\{\underline{N} / \underline{\operatorname{Adj}}\}_{2} \ldots \underline{Y}_{6}\right| \ldots\right]\right)\right]_{4}$

Syntax: $\quad\left[v \operatorname{Pref}_{1}\{\underline{\mathrm{N}}, \underline{\operatorname{Adj}}\}_{2} \mathrm{Suff}_{3}\right]_{4}$

Phonology: $\left[\omega_{0} / \mathrm{eN} / 1 / \ldots / 2 / \ldots / 3\right]_{4}$

This rule can be paraphrased as 'a noun or an adjective, whatever their meaning and pronunciation, can combine with the prefix en-to form a causative verb'. The subscripts mark the links between the different components.

This schema generalizes over all the analysed units in the corpus. However, as we said at the beginning of Section 5, in modern Spanish, only two of the possible schemas are truly productive. These two schemas can be modeled as follows:

(1) Semantics: $\quad$ [Event CAUS ([object $\left.\left.\left.\underline{X}_{5}\right],\left[F \ldots\left|\underline{N}_{2} \ldots \underline{Y}_{6}\right| \ldots\right]\right)\right]_{4}$

Syntax: $\quad\left[v \operatorname{Pref}_{1} \underline{N}_{2} \text { Suff }_{3}\right]_{4}$

Phonology: $[\omega / \mathrm{eN} / 1 / \ldots / 2 / \text { ár/3 }]_{4}$

(2) Semantics: [Event CAUS ([object $\left.\underline{X}_{5}\right],\left[\right.$ Event $I N C\left[\right.$ State BE ${ }_{\text {Asc }}\left(\underline{Y}_{6},\left[\right.\right.$ Property $\left.\left.\left.\left.\left.\left.\underline{\operatorname{Adj}}_{2}\right]\right)\right]\right]\right)\right]_{4}$ Syntax: $\quad\left[\mathrm{vPref}_{1} \underline{\operatorname{Adj}}_{2} \mathrm{Suff}_{3}\right]_{4}$

Phonology: $\left[{ }_{\omega} / \mathrm{eN} / 1 / \ldots / 2 / \mathrm{esé} / 3\right]_{4}$

Note that, in the schema presented above as an interface rule, the only semantic element that persists throughout the corpus is the function CAUS with its argument structure. Productive schema number (2) has a further specified semantic structure, but only accounts for a portion of the corpus.

Note also that the links, marked by the subscripts, do not cut across all three components. Crucially, the phonological segment/eN/ links to the category Prefix in the syntax, but it does not link to anything in the semantics. In other words, the causative meaning is not associated to the en-morpheme (subscript 1), but to the entire morphological schemas in which it occurs (subscript 4).

\subsection{Open questions}


In Section 5.2, we identified some regularities in how the meaning of the base intervenes in the composition of the derived verb's meaning, but these regularities do not even begin to exhaust the possibilities evidenced by the corpus. What part of the meaning of acero ('steel') makes the meaning of enacerar 'to make something have the properties of steel (specifically, its toughness)', instead of, say, 'to cover something with steel'? Or consider a more extreme case: Why do enaceitar, encalar, enfangar mean 'to cover something with a substance (oil, lime, and mud, respectively)', but enlejiar and enterrar mean 'to make something go into a substance (bleach and earth, respectively)?

We can answer by saying that the first speaker who coined the verb used it with that specific meaning, which later speakers have inherited. However, the problem is rather the converse: When confronted with the first occurrence of a neologism whose derivation process is synchronically transparent (like enacerar, 'to make something like steel'), how does a speaker "calculate" the meaning of the derived verb from the meaning of the base and the knowledge she has about the morphological schemas in which the en-prefix occurs and their meanings? We are currently designing a methodology to try to give an answer to this question.

On a different matter, however difficult it is to predict the compositional meaning of these derived verbs, it is even harder to account for the idiosyncratic and/or figurative meanings of many of them, among which we include the cases of "opaque" semantic schemas mentioned above. As an example, consider one of the meanings of the verb encasquetar, 'to teach or make someone learn something, by repeating it insistently', which no longer denotes the action of putting a physical object on someone's head, but an intellective transference ('to put an idea inside someone's head').

Modelling the figurative meaning is not in itself problematic; we can actually do it with the apparatus presented here: [Event $\mathrm{CAUS}$ ([object $\underline{\mathrm{X}}]$, [Event $\mathrm{GO}_{\text {Intel }}([$ Information $\underline{\mathrm{Y}}]$, [Path TO ([object $\underline{Z}]$ )])])], where the function GO is relativized to the semantic field of intellection (as a kind of possession), its Theme argument belongs to the ontological class Information, and the Goal $\mathrm{Z}$ is a human. The problem lies in the lack of a theory-laden description, within the PA framework, of the process whereby we go from a literal semantic schema to a metaphorical one. Here, we forgo even attempting to offer a possible solution.

A third question pertains to the impact that this type of research can have, for instance, in teaching language. Broadly speaking, the PA framework provides insight into the nature of words: they are interconnections of sound, meaning, and syntax, and there is value in teaching and learning them as such. Specifically, for the Spanish verbs we have discussed, the semantic 
schemas we have identified lend themselves to be used as criteria for organizing the verbs into lexical fields, which may help in teaching and learning vocabulary.

Knowledge of non-productive morphological schemas may prove helpful in comprehension, as may the knowledge of the possible phonological changes undergone by the base during incorporation. In turn, knowledge of productive morphological schemas may prove valuable both in comprehension and production.

The generalizations concerning syllabification and stress patterns may prove useful in teaching and learning pronunciation, while the regularities in meaning composition identified in Section 5.2 can help learners predict the meaning of verbs they encounter for the first time.

Finally, a combined description of these verbs, based on (1) the semantic schemas they conform to and (2) their syntactic schemas and thematic roles of the subject and object NPs, can provide learners with valuable help in constructing sentences around them.

\section{Conclusions}

We have presented the analysis of a corpus made up of Spanish causative verbs formed with the prefix en-, within the theoretical and analytical framework of the PA. This has allowed us to offer a unified description of the corpus, as the theory organically integrates the semantic, syntactic, and phonological components of language, and the interactions between them through interfaces.

The derivational morpheme en-thus appears as an interface rule that links structures from the three components in several morphological schemas, only two of which seem to be productive in modern Spanish.

As we saw, the causative morpheme en-is vastly polysemous, even if we take into account that it only occurs in two productive schemas. This makes it difficult to establish its meaning beyond pointing out that it always involves a causative structure serving as a frame for the meaning of the derived verb, which results from its combination with a nominal or adjectival base. We insist on the fact that the causative meaning seems to be associated to the entire morphological schema, rather than to the individual morpheme.

We have found that the base of the verb not only contributes content to its semantic structure, but that it also carries semantic roles (Theme, Goal, etc.). We take this as evidence for the claim that, while part of the phonological component ignores morphosyntactic boundaries, these are quite visible to the semantics, which is able to make an argument out of a piece of structure and assign thematic roles to it, even if this piece of structure is embedded in the role-assigning predicate (verb) itself. 
Furthermore, we have set forth a hypothesis to explain the production of redundancies, or lack thereof, depending on the semantic arguments instantiated in the syntax, based on two constraints of the syntax-semantics interface, which appear to be, to some extent, violable. However, independent evidence is necessary for these constraints.

Although we have identified some regularities, the matter of modelling or even predicting the meaning of the verb from the possible combinations, as well as the problem of accounting for idiosyncratic and figurative meanings (beyond describing them as non-canonical mappings between components), must be left unaddressed.

\section{References}

Booij, Geert \& Jenny Audring, 'Construction Morphology and the Parallel Architecture of grammar', Cognitive Science, special issue on the occasion of the Rumelhart prize for Ray Jackendoff, 2015.

Jackendoff, Ray, Semantic Structures (Cambridge: The MIT Press, 1990)

Jackendoff, Ray, The Architecture of the Language Faculty (Cambridge: The MIT Press, 1997)

Jackendoff, Ray, Foundations of Language (New York: Oxford University Press, 2002)

Jackendoff, Ray, 'A Parallel Architecture perspective on language processing', Brain Research, 1146 (2007), 2-22

Jackendoff, Ray, 'Genesis of a theory of language: From thematic roles (source) to the Parallel Architecture (goal) (Sort of an intellectual memoir)'. Talk given at Yale University, in the spring of 2013 (https://ase.tufts.edu/cogstud/jackendoff/papers/GenesisofPA.pdf).

Jackendoff, Ray, 'In Defense of Theory', Cognitive Science, November (2015), 1-28

Jackendoff, Ray \& Jenny Audring, 'Relational Morphology in the Parallel Architecture'. To appear in The Oxford Handbook of Morphological Theory, ed. by J. Audring \& F. Masini (2016)

Lakoff, George \& Marc Johnson, Metaphors We Live By (Chicago: The University of Chicago Press, 1980)

Leonetti, Manuel, 'Specificity and Differential Object Marking in Spanish', Catalan Journal of Linguistics, 3 (2004), 75-114

Marín, R. \& L. McNaclly, 'Inchoativity, change of state, and telicity: evidence from Spanish reflexive psychological verbs', Natural Language and Linguistic Theory, 29 (2011), 467-502 


\title{
Moliner, María, Diccionario de uso del español (Madrid: Gredos, 2008) [Software]
}

\author{
${ }^{1}$ See, for instance, Ray Jackendoff, Semantic Structures (Cambridge: The MIT Press, 1990), The \\ Architecture of the Language Faculty (Cambridge: The MIT Press, 1997), and Foundations of Language (New \\ York: Oxford University Press, 2002). \\ ${ }^{2}$ Sometimes the mapping bypasses one or two of the components. For instance, [vP V (NP)] is a piece of \\ syntactic structure without links to either phonology or semantics. Interjections are pieces of phonological \\ structure linked to a semantic structure, but without links to the syntax. For more examples, see Ray Jackendoff, \\ Foundations of Language (New York: Oxford University Press, 2002), 'A Parallel Architecture perspective on \\ language processing', Brain Research, 1146 (2007), 2-22, and 'Genesis of a theory of language: From thematic \\ roles (source) to the Parallel Architecture (goal) (Sort of an intellectual memoir)', talk given at Yale University, \\ in the spring of 2013 (https://ase.tufts.edu/cogstud/jackendoff/papers/GenesisofPA.pdf). \\ ${ }^{3}$ See, for instance, Geert Booij \& Jenny Audring, 'Construction Morphology and the Parallel Architecture \\ of grammar', Cognitive Science, special issue on the occasion of the Rumelhart prize for Ray Jackendoff, 2015; \\ and Ray Jackendoff \& Jenny Audring, 'Relational Morphology in the Parallel Architecture'. To appear in The \\ Oxford Handbook of Morphological Theory, ed. by J. Audring \& F. Masini (2016). \\ ${ }^{4}$ Ray Jackendoff, Foundations of Language (New York: Oxford University Press, 2002), p. 369. \\ ${ }^{5}$ Ray Jackendoff, Semantic Structures (Cambridge: The MIT Press, 1990), p. 104. \\ ${ }^{6}$ See, for instance, the classic George Lakoff \& Mark Johnson, Metaphors We Live By (Chicago: The \\ University of Chicago Press, 1980). \\ ${ }^{7}$ Ray Jackendoff, Semantic Structures (Cambridge: The MIT Press, 1990) \\ ${ }^{8}$ About this distinction between the generative and relational functions of morphological schemas, see Geert \\ Booij \& Jenny Audring, 'Construction Morphology and the Parallel Architecture of grammar', Cognitive \\ Science, special issue on the occasion of the Rumelhart prize for Ray Jackendoff, 2015 (p. 4) and Jackendoff, \\ Ray \& Jenny Audring, 'Relational Morphology in the Parallel Architecture', to appear in The Oxford Handbook \\ of Morphological Theory, ed. by J. Audring \& F. Masini (2016) (p. 11). \\ ${ }^{9}$ Geert Booij \& Jenny Audring, 'Construction Morphology and the Parallel Architecture of grammar', \\ Cognitive Science, special issue on the occasion of the Rumelhart prize for Ray Jackendoff, 2015 \\ ${ }^{10}$ Here, the double underlining marks primary stress, and single underlining marks secondary stress. \\ ${ }^{11}$ See, for instance, Manuel Leonetti, 'Specificity and Differential Object Marking in Spanish', Catalan \\ Journal of Linguistics, 3 (2004), 75-114. \\ ${ }^{12}$ Ray Jackendoff, 'Genesis of a theory of language: From thematic roles (source) to the Parallel \\ Architecture (goal) (Sort of an intellectual memoir)'. Talk given at Yale University, in the spring of 2013 \\ (https://ase.tufts.edu/cogstud/jackendoff/papers/GenesisofPA.pdf). \\ ${ }^{13}$ For a discussion of preference rules in Conceptual Semantics, see Ray Jackendoff, Semantic Structures \\ (Cambridge: The MIT Press, 1990), pp. 35-37. \\ ${ }^{14}$ Marín, R. \& L. McNaclly, 'Inchoativity, change of state, and telicity: evidence from Spanish reflexive \\ psychological verbs', Natural Language and Linguistic Theory, 29 (2011), 467-502 (p. 469).
}

